\title{
A survey on knowledge and skills in the early diagnosis of leprosy in general health services at different levels in Shandong province, The People's Republic of China
}

\author{
CHEN SHUMIN, HAN CUNLIAN, LI BING, \\ ZHENG RONGTAO \& ZHANG LIN \\ Shandong Provincial Institute of Dermatology, No.57 Ji Yian Rd, \\ Jinan, Shandong, 250022, People's Republic of China
}

Accepted for publication 15 September 1999

\begin{abstract}
Summary In the late phase of a leprosy control programme, problems arise with regard to the early detection and treatment of a small number of new incident cases. We describe a study in the province of Shandong, People's Republic of China, on the knowledge and skills regarding leprosy of general health service staff, including rural doctors, paramedical doctors at township level, doctors from county general and provincial hospitals and dermatologists. The results showed that there is a continuing need for suitable training programmes for medical staff in the general health services. Most dermatologists had good levels of knowledge and skills and more than $80 \%$ of new cases have been diagnosed in skin clinics in this province since 1990. Their participation in early diagnosis and training of staff should be strengthened.
\end{abstract}

\section{Introduction}

Leprosy control is a long-term project. Even in the late phase in which the goal of elimination of leprosy has been achieved, there is often still a need for some form of leprosy control programme. In this phase, programme managers and planners still face two major problems, i.e. early detection and treatment with multiple drug therapy (MDT) for the small number of incident new cases and rehabilitation for those who are disabled. ${ }^{1}$ From an epidemiological point of view, leprosy is under control and is no longer a public health problem in Shandong province, ${ }^{2}$ which is located in the eastern part of China, with a population of 87 million. In the past 10 years, 50-70 new cases have been detected each year, of whom $20 \%$ have WHO grade 2 disability at diagnosis. ${ }^{2}$ This indicates that there is room for improvement in case finding, to detect all cases at an early stage. Since the prevalence of leprosy in Shandong is very low, with only a few new cases widely scattered in the population, it is not cost-effective to conduct population or rapid surveys to find these few new cases. Even contact survey loses its value because the percentage of new cases detected in this way may accounts only for 
$1.5 \%$ of the total new cases detected in the past 10 years. Utilization of the general health services at all levels in case-finding may help in solving this problem. The objective of this pilot study is to assess the knowledge and skills of general health service staff at different levels in the early diagnosis of leprosy and to use the results for the design of appropriate training programmes.

\section{Materials and methods}

- At provincial level, two general hospitals were visited. All doctors on duty in the internal medicine and surgical departments and the dermatological clinics were interviewed.

- At county level, one general hospital in each of the three counties in Jining prefecture was selected. All doctors on duty in internal medicine and surgical departments were interviewed.

- At township level, all doctors on duty were asked to fill in a questionnaire.

- For rural doctors, we checked the leprosy register book to select the last 50 patients affected by leprosy (cured cases), and then visited the rural doctors based on the patients' villages.

When we arrived at the study areas (hospitals or village health station), the chief of the department or clinic was introduced to us by the local health officer and we then briefly explained our purpose and asked him or her to distribute the structured self-administered questionnaires to the interviewees. The investigators watched the doctors filling in the questionnaires and explained any question that was not understood.

\section{Results}

On the day of the visit, some rural doctors were not on duty. In all, 33 rural doctors from 33 villages, 34 doctors from 13 township hospitals, 27 doctors from county hospitals. 35 doctors from two provincial hospitals and 13 dermatologists from two skin clinics answered the

Table 1. Sex, age, education background and professional experience of medical staff in general health services

\begin{tabular}{|c|c|c|c|c|c|}
\hline & Rural doctor & $\begin{array}{l}\text { Township } \\
\text { doctor }\end{array}$ & County doctor & $\begin{array}{l}\text { Province } \\
\text { doctor }\end{array}$ & Dermatologist \\
\hline \multicolumn{6}{|l|}{ Sex } \\
\hline $\mathbf{M}$ & $31(94)$ & 32 (94) & $22(81)$ & $18(22)$ & $6(46)$ \\
\hline $\mathrm{F}$ & $2(6)$ & $2(6)$ & 5 (19) & 4 (18) & $7(5.4)$ \\
\hline Age (range) & $54(23-68)$ & $46(28-59)$ & $38(23-55)$ & $42(27-58)$ & $4(25-59)$ \\
\hline Education level & & & & & \\
\hline University & $0(0)$ & $24(71)$ & $13(48)$ & $21(95)$ & $10(77)$ \\
\hline $\begin{array}{l}\text { Paramedical } \\
\text { school }\end{array}$ & $11(33)$ & $10(29)$ & $14(52)$ & $1(5)$ & $3(23)$ \\
\hline Other* & $22(67)$ & $0(0)$ & $0(0)$ & $0(0)$ & $0(0)$ \\
\hline $\begin{array}{l}\text { Professional } \\
\text { experience } \\
\text { (years) (range) }\end{array}$ & $28(2-43)$ & $21(5-38)$ & $18(1-29)$ & $19(3-32)$ & $14(2-33)$ \\
\hline
\end{tabular}

Other: trained locally for less than 1 year. 
Table 2. Origin of knowledge on leprosy and knowledge and skills in early diagnosis of leprosy among staff in general health services at different levels

\begin{tabular}{lcc}
\hline & Staff in general health services & Dermatologists \\
\hline & $n=116(\%)$ & $n=13(\%)$ \\
$\begin{array}{l}\text { Origin of knowledge on leprosy } \\
\text { University/medical school }\end{array}$ & $85(73.28)$ & $13(100)$ \\
Lecture & $62(53.45)$ & $10(77)$ \\
Reading materials & $57(49.14)$ & $13(100)$ \\
Basic knowledge on leprosy & $70(60.34)$ & $13(100)$ \\
Pathogen of leprosy & $90(77.59)$ & $11(85)$ \\
Life-long medication & $15(12.93)$ & $8(62)$ \\
Multidrug therapy & $37(31.90)$ & $10(76.92)$ \\
Recognition of early symptoms and signs of leprosy & $13(100)$ \\
Early symptoms* & $11(9.48)$ & \\
Early signs of leprosy** & & \\
\end{tabular}

*Defined as numbness or tingling of extremities; ** defined as anaesthetic, pale or erythematous patches with or without peripheral nerve enlargement.

questionnaire. Their sex, age, education background and professional experience are presented in Table 1.

A comparison of the origin of leprosy knowledge, basic leprosy knowledge, and knowledge and skills in early diagnosis of leprosy between dermatologists and the staff in general health services is shown in Table 2. Since the staff at different levels play different roles in a leprosy control programme, further details will be given as below. Regarding the pathogen of leprosy, $18 \%$ of village doctors, $6 \%$ of township hospital doctors, $19 \%$ of doctors in county hospitals and $14 \%$ of doctors from internal medicine and surgical departments in provincial general hospitals did not know about Mycobacterium leprae. Information regarding the duration of treatment and MDT showed that $9 \%$ of rural doctors, $12 \%$ of township doctors, $11 \%$ of county doctors, $73 \%$ of provincial doctors and $15 \%$ of dermatologists erroneously believed that a leprosy patient should take anti-leprosy drug(s) for life, once a diagnosis was made. None of the rural, township and provincial doctors, $44 \%$ of county doctors and $38 \%$ of dermatologists in this investigation knew about MDT. The majority of doctors investigated, except for dermatologists, could not recognize the early sign of leprosy. This may simply reflect their lack of experience in the early diagnosis of leprosy in their medical practice, as shown in Table 3, although some had experience in diagnosing leprosy cases at the late stages

Table 3. Experience with leprosy cases among medical staff at different level

\begin{tabular}{|c|c|c|c|c|c|}
\hline & \multirow[b]{2}{*}{$n$} & \multicolumn{2}{|c|}{ Seeing leprosy cases } & \multicolumn{2}{|c|}{ Consulted by leprosy cases } \\
\hline & & Yes $(\%)$ & No $(\%)$ & Yes $(\%)$ & No $(\%)$ \\
\hline Rural doctor & 33 & $33(100)$ & $0(0)$ & $20(61)$ & $13(39)$ \\
\hline Township doctor & 34 & $18(53)$ & $16(47)$ & $5(15)$ & $29(85)$ \\
\hline County doctor & 27 & $15(56)$ & $12(44)$ & $3(11)$ & $24(89)$ \\
\hline Province doctor & 22 & $9(41)$ & $13(59)$ & $2(9)$ & $20(91)$ \\
\hline Dermatologist & 13 & $4(31$ & $9(69)$ & $10(77)$ & $3(23)$ \\
\hline Total & 129 & $79(61)$ & $50(39)$ & $40(31)$ & $89(69)$ \\
\hline
\end{tabular}


of illness or with deformity. In terms of skills in the examination of peripheral nerves, the correct answers, except for dermatologists, were given by $36 \%$ of rural doctors, $6 \%$ of doctors from township hospitals, $18 \%$ of doctors from county general hospitals and $0 \%$ of doctors from provincial general hospitals. Seventy percent of rural doctors, $71 \%$ of township doctors, $59 \%$ of county doctors and $77 \%$ of provincial doctors did not know that a skin smear or biopsy may be indicated for the confirmation of diagnosis in a suspected leprosy case.

\section{Discussion}

The deformity rate among newly diagnosed leprosy cases is an important indicator in the assessment of case-finding activity. ${ }^{3}$ Disability rates as high as $30 \%$ (WHO grade 1-2) among newly detected cases have been reported in some countries. ${ }^{4,5}$ Recently, a report from the International Federation of Anti-Leprosy Association (ILEP) and WHO showed disability rates (WHO grade 2-3) in different leprosy control programmes ranging from 0 to $79 \% .^{6}$ In China, disability rates have been variously reported as $19.4-36 \% .^{7-11}$ The disability rate among newly detected leprosy cases in Shandong province has been about $20 \%$ on average in the last 10 years. This indicates that there is room for improvement in case-finding, even in a low endemic situation. In some leprosy control programmes such as that in Malaysia, in which the goal of elimination of leprosy has been achieved, the disability rate among newly detected cases can be as low as $5 \%$ (personal communication). The detection method and case-finding activity, ${ }^{12}$ as well as the epidemiological situation, can influence the disability rate among newly detected leprosy cases. Theoretically, however, the lower the disability rate the better, because early diagnosis and treatment with MDI are very important in reducing the risk of disability, although the disability cannot be avoided completely. ${ }^{4}$

Many approaches to case finding have been used in different leprosy control programmes according to the local situation. In Shandong province, case detection methods such as population survey and rapid survey are no longer cost-effective, since the prevalence is too low $(0.037 / 10,000$ population in 1994) and the distribution of leprosy cases is too scattered in the population. Contact examination is an important method of case-finding, which is still used in many leprosy control programmes. In the late phase of a leprosy control programme with the very low prevalence in Shandong province, however, fewer and fewer new leprosy cases are detected in this way. A recent analysis showed that 97 (12.4\%) out of 773 newly detected cases between 1987 and 1996 had a family history of leprosy (unpublished data).

New cases detected through contact examination account for only $1.5 \%$ of new cases detected in the past 10 years. Usually, there is a time gap between the identification of an index case and the onset of disease among family numbers. Furthermore, the fact that the examination of household contacts is done only once, when diagnosis of the index case is made, is seldom useful for the finding of a secondary case in a low endemic situation. The time between an index case and a secondary case in Shandong is, on average, 10 years (unpublished data). Obviously, it is impossible to carry out contact examinations year by year for many years, if only because they may create social stigma. Utilization of general services in case-finding would therefore be one of the options in solving this problem in the long run.

In most medical and paramedical schools in Shandong province, a short course (usually $2-3 \mathrm{~h}$ ) on leprosy is available (Table 2). However, knowledge and skills related to the early diagnosis of leprosy among the doctors in this investigation were low. This is partly related to the lack of experience in practice. In a group of 335 new cases reported in China, 150 cases 
(44.38\%) consulted general health services at different levels for 326 person times for their disease before the diagnosis of leprosy was made. Two hundred and twenty-eight $(70 \%)$ of the patients in this group were misdiagnosed on their first visits. ${ }^{11}$ In another analysis of 50 new leprosy cases misdiagnosed for a long time, the main reason for the misdiagnosis was that the staff in general health services at different levels lacked of basic knowledge and expenence. ${ }^{13}$ Many doctors in this study had some experience in contacting cured or deformed leprosy cases, but not new cases. A study conducted in India also showed that the field investigators could initially miss about $35 \%$ of cases of leprosy, mostly with early manifestations. After training and experience, the proportion of missed cases decreased to about $20 \% .^{14}$

In the past, training programmes for rural doctors and doctors at township level involved in the leprosy control programme, did not include task assignment and orientation on the early diagnosis of leprosy. The main role they played in a vertical leprosy control programme was very limited, such as guiding the way to the patient's home or delivering medication to patients. Even in rapid surveys, they were asked to report suspects with late signs of leprosy such as lagophthalmos, claw hand or painless foot wound. Our findings show that in order to detect all new cases as early as possible, the participation of dermatologists in early diagnosis and training of staff should be strengthened. Incorporation of leprosy in the curricula of medical faculties and paramedical schools should continue with an opportunity to see and examine patients whenever possible.

Dermatologists, in general, have good knowledge and skill in early diagnosis of leprosy. An important incidental finding of this study was that more than $80 \%$ of new cases have been diagnosed in skin clinics at different levels in Shandong since 1990. The relationship between dermatologist and leprosy control programme manager should be strengthened. Skin clinics at different levels should be part of the whole programme. Dermatologists should also be involved in the training programme. They can form a bridge between the leprosy control programme manager and the staff working in general health services, to ensure the early diagnosis of leprosy.

\section{References}

${ }^{1}$ Feenstra P. Sustainability of leprosy control services in low endemic situations. Trop Geograph Med, 1994; 46: 65-71.

2 Chen S. Options for leprosy control programme in Shandong Province, China. Thesis, $31^{\text {st }}$ International Course in Health Development, 1995, Amsterdam, The Netherlands.

3 WHO. Epidemiology of leprosy in relation to control. Report of a WHO Study Group. Technical Report Series 716, WHO, Geneva, 1985.

${ }^{4}$ Watson JM. Disability control in a leprosy control programme. Lepr Rev, 1989; 60: 169-177.

5 Wittenhorst B, Vree ML, Ten Ham PBG et al. The national leprosy control programme of Zimbabwe: a data analysis. Lepr Rev, 1998; 69: 46-56.

6 Smith WCS. Prevention of disability in leprosy - ILEP Medical Bulletin. Lepr Rev, 1996; 67: 68-72.

7 Wu GC et al. Analysis on 329 leprosy new cases detected in recent 10 years in Qian Xinan prefecture, Gui Zhou province. Chinese J Lepr, 1991; 7: 90-91.

8 He R et al. Analysis on 407 newly detected leprosy cases in Hubei. Chinese J Lepr, 1994; 10: 99-100.

${ }^{9}$ Lai ZJ et al. Analysis on 1493 newly detected leprosy cases. Chinese J Lepr, 1994; 10: 160-162.

10 Liau DZ et al. A report of 177 new leprosy cases detected in recent 10 years in Xu Zhou. Chinese J Lepr, $1995 ; 11$ : 199-200.

11 Sun HT et al. Analysis on 335 new leprosy cases diagnosed in skin clinic. Chinese J Lepr, 1991; 7: 79-80.

12 Ishida Y, Biswas AK, Guglielmell E. Detection mode of leprosy and its disability grading in Khulna City, Bangladesh. Nihon Hansenbyo Gakkai Zasshi, 1998; 67: 391-400 (abstract).

13 Ma DJ. Analysis on 50 misdiagnosed leprosy cases. Chinese J Lepr, 1990; 6: 231-232.

14 Gupte NB. Diagnostic problems of early leprosy in field studies. Ind J Lepr, 1994; 66: 463-472. 